\title{
3D Printing Bioactive Polymer Composites for Multifunctional Wound Healings ${ }^{\dagger}$
}

\author{
Anna Goncharenko ${ }^{1}$, Vladimir Chrishtop ${ }^{1}$ and Sofia Morozova ${ }^{1, *}$ \\ 1 International Institute Solution Chemistry of Advanced Materials and Technologies, ITMO University, \\ 197101 St. Petersburg, Russia.; goncharenko@scamt-itmo.ru (A.G.); chrishtop@scamt-itmo.ru (V.C.) \\ * Correspondence: morozova@scamt-itmo.ru \\ + Presented at 1st International Electronic Conference on Applied Sciences, 10-30 November 2020; Available \\ online: https://asec2020.sciforum.net/.
}

Published: 10 November 2020

\begin{abstract}
A wound is specifically referring to a sharp injury which damages the epidermis of the skin. The reasons of that surgery, burns, trauma and chronic diseases. An essential part of medical and pharmaceutical wound care is dressing. The wound dressing or patch perform the role of protection barrier from infection, keeps in appropriate moisture and $\mathrm{pH}$ levels, and promotes the healing process. The addition of components such as biologically active molecules and nanoparticles to the dressing matrix helps prevent or treat infection, detect a number of parameters, such as moisture level or the presence of a pathogen, etc., and can also accelerate wound healing through biological pathways. This study aims to 3D print multifunctional hydrogel wound dressings with programmable passive release of antimicrobial and healing agents like growth factor. Aluminum boehmite is dispersed into the hydrogel matrix, which promotes wound healing. The system also includes a gradient distribution of fibroblast growth factor (FGF-2), which in turn helps to accelerate the healing process. The work consists of chemical, engineering, and biological parts. Optimization of the hydrogel composition (modification of the synthesis of chitosan, the addition of other hydrogels, for example, CNC, PEG), as well as the selection of printing parameters (pressure, printing plate temperature, printing speed) and fixing the resulting pattern (glutaraldehyde, UV crosslinking) are the stages of chemical engineering parts. Biology includes in vitro cytological studies, as well as the study of the effect of the uniform and gradient presence of FGF on the rate of wound healing in vivo.
\end{abstract}

Keywords: 3D printing; wound healing; hydrogel; alumina; FGF-2; gradient distribution.

Acknowledgments: This work was supported by the Ministry of Education and Science of Russia (project No. 075-15-2019-1896).

Publisher's Note: MDPI stays neutral with regard to jurisdictional claims in published maps and institutional affiliations.

C 2020 by the authors. Submitted for possible open access publication under the terms and conditions of the Creative Commons Attribution (CC BY) license

(http://creativecommons.org/licenses/by/4.0/). 